\title{
Preface: Current advances in analysis, modelling and mitigation of the costs of natural hazards
}

\author{
H. Kreibich ${ }^{1}$, L. M. Bouwer ${ }^{2}$, and R. Schwarze ${ }^{3}$ \\ ${ }^{1}$ German Research Centre for Geosciences GFZ, Section Hydrology, Potsdam, Germany \\ ${ }^{2}$ Deltares, Delft, the Netherlands \\ ${ }^{3}$ Helmholtz Centre for Environmental Research UFZ, Leipzig, Germany \\ Correspondence to: H. Kreibich (heidi.kreibich@gfz-potsdam.de)
}

\section{Introduction}

Assessments of the costs of natural hazards supply crucial information for decision support and policy development related to natural hazard management and climate change adaptation (Kreibich et al., 2014). These costs comprise damage due to natural hazards as well as costs of prevention, risk mitigation and responses to natural hazards. However, recent work shows that cost assessments are often still incomplete, reliable impact data are scarce (Handmer et al., 2005; Gall et al., 2009), damage estimation methods are often crude and insufficient (Meyer et al., 2013; Merz et al., 2010), and the knowledge about costs and benefits of precautionary measures is scattered (Hudson et al., 2014; Bubeck et al., 2012; Kreibich et al., 2011, 2012, 2015). The EU Seventh Framework Programme project CONHAZ - Costs of Natural Hazards (http://conhaz.org/) - collected and reviewed current knowledge on methods for assessing individual cost types, such as direct damage to housing; indirect losses in the macroeconomy; costs due to intangible effects, e.g. on people or the environment; and costs of risk reduction. The project showed how these methods are applied to various natural hazards, including floods, droughts, alpine and coastal hazards.

In this special issue, Meyer et al. (2013) present the results of this review and provide recommendations on how to reduce or handle shortcomings and uncertainties by improving data sources and cost assessment methods. Further recommendations address how risk dynamics due to climate and socio-economic change can be better considered, how costs are distributed and how risks can be transferred, and in what ways cost assessment can function as part of decision support. The session NH9.3 "Costs of Natural Hazards" at the 2012 European Geosciences Union (EGU) General Assem- bly further provided the possibility for a wider discussion and presentations of new results and developments. This special issue is dedicated to results presented at this EGU session, and it includes papers beyond the CONHAZ project.

Current research on costs of natural hazards comprises overlapping topics, which can be categorised as follows: damage documentation and analyses of past events; damage modelling and risk analyses; and precautionary measures including insurance. Individual contributions to these topics are discussed in the following sections. These topics are treated in subsequent sections. Finally, we sum up with a number of overall conclusions and perspectives on the analysis of costs of natural hazards.

\section{Damage documentation and analyses of past events}

Detailed event documentations are essential for the analysis of past events, their consequences and responses to them (e.g. Schröter et al., 2015; Kreibich et al., 2007). Additionally, they are necessary for risk model development and validation and for the improvement of the risk management (Schröter et al., 2014; Falter et al., 2014; Kreibich et al., 2014). More efforts to collect detailed damage data are needed, as well as the development of standardised methods and the implementation of comprehensive documentation and event analysis routines. Particularly due to changing risks, regular reexaminations of the effectiveness of implemented risk management strategies are necessary, for which detailed event analyses, including cost estimates, are an important component.

The development of standardised approaches for damage data collection in the field after a flood event is essential for the improvement of our evidence base. As presented in this special issue, Molinari et al. (2014) developed a method 
to collect data on flood damage and applied it after recent events in the regions of Umbria and Sicily in Italy. The paper proposes a procedure for collecting and storing damage information, which includes the development of data collection forms, explanation and instruction kits for surveyors and guidance for electronic data storage. Damage information of the residential and commercial sectors on the individual building level was collected from two flood events. The information on loss ratios collected in the field was compared with predicted loss ratios from different damage models, which showed significant deviations. Petrucci (2013) developed a methodology for damage assessment of landslide events. The method assesses direct, indirect and intangible damage indices at the municipal and regional scale, based on a minimum of data. An application of the method in Italy revealed that roads were the most vulnerable elements at risk. Road damage leads additionally to intangible damage for people who are forced to use alternative roads for their daily activities. Indirect costs are mainly associated with displacement of people, often only for short periods.

Pfurtscheller (2014) analysed the 2005 flood event in the federal state of Tyrol (Austria). The main objective was the development of a simplified empirical approach to assess the regional-economic impacts without using macroeconomicmodelling techniques. Companies from all sectors of the economy were surveyed to identify the main drivers of indirect effects. Disrupted transport networks were identified as the main cause of the decline in business revenues. It was also revealed that companies which were affected directly by damage to structure or machinery suffered more from declining revenues than companies without any direct losses. André et al. (2013) create a database of insurance claims data for two major storm surges in the French Atlantic coastal region: Johanna occurred on 10 March 2008, and Xynthia occurred on 28 February 2010. Both were extreme events in terms of wind speeds, water levels and waves along the coast. A standardised methodology was developed for the collection of insurance data at two levels: indemnity payments and loss adjustment reports. The latter adds process information and asset characteristics to the former based on information from site visits by certified experts. The paper studies the functional relationship of insurance cost data at different levels and process characteristics (water depth). The authors cannot establish damage functions with a good degree of certainty based on payments because of lacking observations on asset properties such as building resistance. A standardised methodology of loss adjustment reporting and nesting of insurance data at different levels is developed, which could in future contribute to improved damage functions based on insurance data.

To investigate temporal changes of risk, Schwendtner et al. (2013) undertook loss estimations of a particular debris flow event for different points in time. The focus was on land use change and settlement expansion between 1954 and 2006. The event occurred in August 1987; affected the mu- nicipality Martell in South Tyrol, Italy; and resulted in a total cost of EUR 25 million. The method applied is based on the use of a vulnerability curve which was developed for the specific area, based on empirical damage data of the 1987 event. A loss estimation was carried out in order to visualise the risk evolution in a period of 52 years (1954 to 2006). The results show a significant increase in the extent of the built environment, which consequently reflects an increase of the potential overall loss over the years.

\section{Damage modelling and risk analyses}

Although damage and risk modelling is an essential part of risk management, it has not received much scientific attention in the past. Thus, many damage models have in common that complex damaging processes are described by overly simple, deterministic approaches (Meyer et al., 2013; Merz et al., 2010). Just recently more sophisticated multiparameter and even probabilistic modelling approaches have been developed for loss assessments (e.g. Elmer et al., 2010; Kreibich et al., 2010; Schröter et al., 2014). Additionally, damage models are frequently transferred in time and space, and across damage processes without giving sufficient justification. More effort is needed for the development of improved models, and more uncertainty analysis and model validations need to be undertaken (e.g. Seifert et al., 2010; Gerl et al., 2014).

In this special issue, Jongman et al. (2012) present a qualitative and quantitative assessment of seven flood damage models, using two case studies of past flood events in Europe. The qualitative analysis shows that modelling approaches vary strongly, and that current methodologies for estimating infrastructural damage are less developed than methodologies for the estimation of damage to buildings. The quantitative results show that the model results are very sensitive to uncertainty in both vulnerability and exposure, whereby the first has a larger effect than the latter. Thus, care needs to be taken when using aggregated land use data for flood risk assessment, and it is essential to adjust asset values to the regional economic situation and property characteristics. A flexible but consistent European framework should be developed that applies best practices from existing models while providing room for including necessary regional adjustments. Brémond et al. (2013) review damage functions for agriculture which were used in 42 studies which undertook economic appraisals of flood management projects. As a basis for the analyses, a conceptual framework of damage categories is proposed for the agricultural sector. The main recommendations are that further improvements are needed for crop damage functions. But there is also a need to develop damage functions for other agricultural damage categories, including farm buildings and their contents. Finally, a farm scale approach needs to be used to cover all possible agricultural damage, and in particular loss of activity. 
A novel approach to increase our understanding of the occurrence of flood damage to buildings is put forward by Merz et al. (2013). Their study uses two multivariate statistical approaches (regression trees and bagging trees), which they hypothesise are more effective compared to traditional methods, as the dependence of damage on flood parameters is often non-linear, and different parameters interact. With this approach, they build relations between different flood parameters (including water depth, flow velocity, and duration), early warning, precaution, experience, building characteristics, and socio-economic indicators. They find that, apart from water depth, building floor space, building value, and inundation duration are particularly important. They show that tree-based damage modelling approaches often outperform traditional models, including multivariate ones.

Gil et al. (2013) evaluate the economic impacts of a drought event on the agricultural sector and how different effects are transmitted from primary production to industrial output and related employment. The direct drought impacts on agricultural productivity are measured through a direct attribution model. Indirect impacts on employment and the agri-food industry are evaluated through a nested indirect attribution model. Chains of elasticity are used to measure the transmission of water scarcity effects from agricultural production to macroeconomic variables. Results show that drought impacts are most important for sectors directly dependent on water abstractions and precipitation but less relevant at the macroeconomic level.

The paper of Rheinberger et al. (2013) presents a framework to estimate proportional loss functions for debris flow events. Debris flows are a particularly destructive form of fast-moving landslides. The authors apply a double generalised linear regression model to study an insurance data set comprising actuarial building values and the costs of repair or replacement of 132 buildings. These buildings were damaged by five debris flow events, which occurred in Switzerland during the late 1980s and early 2000s. Industrial and agricultural buildings are seen to be more vulnerable to debris flows than residential buildings. The application of proportional loss predictions is of practical value. For example, modern GIS techniques allow for combining proportional loss functions with hazard maps and databases of insurance contracts to create proper risk maps. Such risk maps could help hazard managers to identify at-risk areas and to prioritise among risk mitigation needs. Second, private property insurers could use the loss predictions to offer individualised contracts that better reflect each homeowner's risk. The paper recommends establishing and maintaining a central damage database for debris flow damage.

Exposure assessment is another important component of risk analyses. Beckers et al. (2013) present a new methodology to model residential land use evolution and its application in a flood risk analysis and projection for the future. Based on a "dry" and a "wet" climate scenario, the method is applied to study the evolution of flood damage by 2100 along the river Meuse. Nine urbanisation scenarios were developed: three of them assume a "current trend" land use evolution, leading to a significant urban sprawl, while six others assume a dense urban development. According to the dry scenario, the flood discharge is expected not to increase. In this case, land use changes increase flood damage by 1 to $40 \%$ in 2100 . In the wet scenario, the relative increase in flood damage is 540 to $630 \%$. In this extreme scenario, the influence of climate on the overall damage is 3 to 8 times higher than the effect of land use change.

\section{Precautionary measures including insurance}

Modern, integrated risk management includes small-scale, private precautionary measures (Bubeck et al., 2015). Such measures are often voluntary and depend on the motivation of the people to protect themselves (Bubeck et al., 2013). It is believed that these measures are effectively reducing damage; however, quantitative analyses are scarce and fragmented (e.g. Botzen et al., 2009; Kreibich et al., 2005). Thus, for cost-effective risk management, more knowledge about the potential of mitigation measures is required, e.g. about their damage-reducing effects and under which conditions and to what extend they are operationally used.

In this special issue, Poussin et al. (2012) present a study about the potential of semi-structural and non-structural adaptation strategies to reduce future flood risk at the river Meuse in the Netherlands. The results show that annual flood risk may increase by up to $185 \%$ in 2030 compared with 2000. Risk-reduction capacity of spatial zoning is between 25 and $45 \%$, via limiting and regulating developments in flood-prone areas. The mitigation strategies dry-proofing, wet-proofing, and the combination of dry- and wet-proofing in residential areas show that these strategies have a riskreduction capacity of between 21 and $40 \%$, depending on their rate of implementation. Combining spatial zoning and mitigation measures could reduce the increase in risk by up to $60 \%$.

Bubeck et al. (2013) compare the damage suffered by households in two consecutive flooding events in Germany in 1993 and 1995. They demonstrate that substantial damage reduction can be achieved through increased risk mitigation efforts of flood-prone households. The damage reduction is observed both in the directly impacted buildings and in the neighbouring buildings due to lower levels of contaminated flood waters. Given their finding of learning from flood experience, and considering the fact that flood extremes are to increase in the future (so that learning from the past becomes ever more difficult), they recommend further efforts of awareness raising and incentives to act precautionarily. Flood insurance policies that are specifically designed to stimulate flood mitigation measures in advance by rewarding precautionary behaviour with premium reductions seem most promising. 
In their contribution to this special issue, Boyer and Nyce (2013) model the cost of providing insurance coverage against natural hazards, considering explicitly the presence of governments as a third layer of last-resort insurance (following primary insurers and reinsurers). The welfare effects of a government supplying insurance are far from trivial since such public intervention will affect the price of insurance and will also impact the tax base needed, which is modelled with citizens becoming investors of government (re)insurance. Using an economic model, they derive the conditions when such a three-tier-layer system of (re)insurance increases social welfare. They demonstrate that governmentprovided (re)insurance unambiguously improves public welfare if and only if it is geared specifically at poor people, regions or social groups, with a low risk-bearing capacity. Paudel et al. (2013) estimate insurance premiums for coverage against flood risk in the Netherlands. Bayesian inference is applied to estimate flood risk for 53 dyke ring areas, focused particularly on data scarcity and extreme behaviour of catastrophe risk. Flood insurance premiums are estimated using two different methods that account in different ways for an insurer's risk aversion and the dispersion rate-of-loss data. The results are interesting for the discussion of insurers about the introduction of flood insurance in the Netherlands, which is currently not generally available.

\section{Conclusions and perspectives}

Modelled results on the costs of natural hazards are highly uncertain, particularly due to the lack of sufficient, comparable and reliable data. Meyer et al. (2013) suggest that a framework for supporting data collection should be established at the European level, for object-specific ex post damage data and also for risk mitigation costs. Open-access European and national databases should be developed which ensure consistency, sufficiently detailed information and minimum data quality standards. Damage data also need to be differentiated according to different loss types. Coarse data, like aggregated damage data per event, are not helpful for understanding damaging processes, for developing damage models and often not even for validation purposes or evaluations of the risk management strategy.

Basically, for all natural hazards a better understanding of the damaging processes is necessary also for model improvements. Multi-parameter damage models seem to significantly reduce the uncertainty of direct damage estimation, compared to traditional methods (e.g. Merz et al., 2013). To identify and quantify the main sources of uncertainty, more method comparisons and sensitivity and uncertainty analyses should be undertaken (e.g. Jongman et al., 2012).

Besides direct costs, increasingly more focus is placed on indirect effects, also because these impacts have been perceived to be dominant in many major recent events, such as Hurricane Katrina in 2005, the flooding in Thailand in 2011 and Hurricane Sandy in New York in 2012. To improve the assessment of indirect costs, more knowledge and modelling approaches are needed on the functioning of markets outside the state of equilibrium and at different spatial scales (e.g. Gil et al., 2013).

For the estimation of the total costs of risk reduction and mitigation, particularly a better estimation of the benefits and costs of non-structural measures is important, as these may substantially influence the size of actual losses (Bubeck et al., 2012; Kreibich et al., 2011). More knowledge is necessary on the impacts of global change on future costs of natural hazards and costs of adaptation to these changes (e.g. Paudel et al., 2013).

Over the past few years, attention to costs of natural hazards has increased. Step by step, our empirical and analytical skills and approaches for cost assessment are improving, as we have shown here. Cost assessments that are able to better support risk management will need to include all relevant cost types, take account of and communicate uncertainties transparently, and consider the dynamics arising from changing risks and socio-economic developments (Meyer et al., 2013; Kreibich et al., 2014). This is essential to arrive at better-informed decisions on the reduction of natural hazard risks.

Acknowledgements. The organisation of this special issue and some of the work presented was supported by the European Community's Seventh Framework Programme through the Coordination Action Project CONHAZ, grant agreement number 244159. We would like to thank the journal managing editor, Fausto Guzzetti, in conjunction with the editorial staff at Copernicus for their support and encouragement.

\section{References}

André, C., Monfort, D., Bouzit, M., and Vinchon, C.: Contribution of insurance data to cost assessment of coastal flood damage to residential buildings: insights gained from Johanna (2008) and Xynthia (2010) storm events, Nat. Hazards Earth Syst. Sci., 13, 2003-2012, doi:10.5194/nhess-13-2003-2013, 2013.

Beckers, A., Dewals, B., Erpicum, S., Dujardin, S., Detrembleur, S., Teller, J., Pirotton, M., and Archambeau, P.: Contribution of land use changes to future flood damage along the river Meuse in the Walloon region, Nat. Hazards Earth Syst. Sci., 13, 2301-2318, doi:10.5194/nhess-13-2301-2013, 2013.

Botzen, W. J. W., Aerts, J. C. J. H., and van den Bergh J. C. J. M.: Willingness of homeowners to mitigate climate risk through insurance, Ecol. Econom., 68, 2265-2277, 2009.

Boyer, M. M. and Nyce, C. M.: Insuring catastrophes and the role of governments, Nat. Hazards Earth Syst. Sci., 13, 2053-2063, doi:10.5194/nhess-13-2053-2013, 2013.

Brémond, P., Grelot, F., and Agenais, A.-L.: Review Article: Economic evaluation of flood damage to agriculture - review and analysis of existing methods, Nat. Hazards Earth Syst. Sci., 13, 2493-2512, doi:10.5194/nhess-13-2493-2013, 2013. 
Bubeck, P., Botzen, W. J. W., Kreibich, H., and Aerts, J. C. J. H.: Long-term development and effectiveness of private flood mitigation measures: an analysis for the German part of the river Rhine, Nat. Hazards Earth Syst. Sci., 12, 3507-3518, doi:10.5194/nhess-12-3507-2012, 2012.

Bubeck, P., Botzen, W. J. W., Kreibich, H., and Aerts, J. C. J. H.: Detailed insights into the influence of flood-coping appraisals on mitigation behaviour, Global Environ. Change, 23, 5, 1327 1338, 2013.

Bubeck, P., Kreibich, H., Penning-Rowsell, E., Botzen, W. W., de Moel, H., and Klijn, F.: Explaining differences in flood management approaches in Europe and the USA - A comparative analysis, J. Flood Risk Manage., doi:10.1111/jfr3.12151, in press, 2015.

Elmer, F., Thieken, A. H., Pech, I., and Kreibich, H.: Influence of flood frequency on residential building losses, Nat. Hazards Earth Syst. Sci., 10, 2145-2159, doi:10.5194/nhess-10-21452010, 2010.

Falter, D., Nguyen, D., Vorogushyn, S., Schröter, K., Hundecha, Y., Kreibich, H., Apel, H., Theisselmann, F., and Merz, B.: Continuous, large-scale simulation model for flood risk assessments: proof-of-concept, J. Flood Risk Manage., doi:10.1111/jfr3.12105, in press, 2014.

Gall, M., Borden, K. A., and Cutter, S. L.: When do losses count? Six fallacies of natural hazards loss data, B. Am. Meteorol. Soc., 90, 799-809, 2009.

Gerl, T. M., Bochow, M., and Kreibich, H.: Flood Damage Modeling on the Basis of Urban Structure Mapping Using HighResolution Remote Sensing Data, Water, 6, 2367-2393, 2014.

Gil, M., Garrido, A., and Hernández-Mora, N.: Direct and indirect economic impacts of drought in the agri-food sector in the Ebro River basin (Spain), Nat. Hazards Earth Syst. Sci., 13, 2679 2694, doi:10.5194/nhess-13-2679-2013, 2013.

Handmer, J., Abrahams, J., Betts, R., and Dawson, M.: Towards a consistent approach to disaster loss assessment across Australia, The Aus. J. Emerg. Manage., 20, 10-18, 2005.

Hudson, P., Botzen, W. J. W., Kreibich, H., Bubeck, P., and Aerts, J. C. J. H.: Evaluating the effectiveness of flood damage mitigation measures by the application of propensity score matching, Nat. Hazards Earth Syst. Sci., 14, 1731-1747, doi:10.5194/nhess-141731-2014, 2014.

Jongman, B., Kreibich, H., Apel, H., Barredo, J. I., Bates, P. D., Feyen, L., Gericke, A., Neal, J., Aerts, J. C. J. H., and Ward, P. J.: Comparative flood damage model assessment: towards a European approach, Nat. Hazards Earth Syst. Sci., 12, 3733-3752, doi:10.5194/nhess-12-3733-2012, 2012.

Kreibich, H., Thieken, A. H., Petrow, Th., Müller, M., and Merz, B.: Flood loss reduction of private households due to building precautionary measures - lessons learned from the Elbe flood in August 2002, Nat. Hazards Earth Syst. Sci., 5, 117-126, doi:10.5194/nhess-5-117-2005, 2005.

Kreibich, H., Müller, M., Thieken, A. H., and Merz, B.: Flood precaution of companies and their ability to cope with the flood in August 2002 in Saxony, Germany, Water Resour. Res., 43, W03408, doi:10.1029/2005WR004691, 2007.

Kreibich, H., Seifert, I., Merz, B., and Thieken, A. H.: Development of FLEMOcs - A new model for the estimation of flood losses in companies, Hydrol. Sci. J., 55, 1302-1314, 2010.
Kreibich, H., Christenberger, S., and Schwarze, R.: Economic motivation of households to undertake private precautionary measures against floods, Nat. Hazards Earth Syst. Sci., 11, 309-321, doi:10.5194/nhess-11-309-2011, 2011.

Kreibich, H., Christenberger, S., and Schwarze, R.: Corrigendum to "Economic motivation of households to undertake private precautionary measures against floods" published in Nat. Hazards Earth Syst. Sci., 11, 309-321, 2011, Nat. Hazards Earth Syst. Sci., 12, 391-392, doi:10.5194/nhess-12-391-2012, 2012.

Kreibich, H., van den Bergh, J. C. J. M., Bouwer, L. M., Bubeck, P., Ciavola, P., Green, C., Hallegatte, S., Logar, I., Meyer, V., Schwarze, R., and Thieken, A. H.: Costing natural hazards, Nat. Clim. Change, 4, 303-306, 2014.

Kreibich, H., Bubeck, P., Van Vliet, M., and De Moel, H.: A review of damage-reducing measures to manage fluvial flood risks in a changing climate, Mitig. Adapt. Strat. Global Change, doi:10.1007/s11027-014-9629-5, in press, 2015.

Merz, B., Kreibich, H., Schwarze, R., and Thieken, A.: Review article "Assessment of economic flood damage", Nat. Hazards Earth Syst. Sci., 10, 1697-1724, doi:10.5194/nhess-10-16972010, 2010.

Merz, B., Kreibich, H., and Lall, U.: Multi-variate flood damage assessment: a tree-based data-mining approach, Nat. Hazards Earth Syst. Sci., 13, 53-64, doi:10.5194/nhess-13-53-2013, 2013.

Meyer, V., Becker, N., Markantonis, V., Schwarze, R., van den Bergh, J. C. J. M., Bouwer, L. M., Bubeck, P., Ciavola, P., Genovese, E., Green, C., Hallegatte, S., Kreibich, H., Lequeux, Q., Logar, I., Papyrakis, E., Pfurtscheller, C., Poussin, J., Przyluski, V., Thieken, A. H., and Viavattene, C.: Review article: Assessing the costs of natural hazards - state of the art and knowledge gaps, Nat. Hazards Earth Syst. Sci., 13, 1351-1373, doi:10.5194/nhess-13-1351-2013, 2013.

Molinari, D., Menoni, S., Aronica, G. T., Ballio, F., Berni, N., Pandolfo, C., Stelluti, M., and Minucci, G.: Ex post damage assessment: an Italian experience, Nat. Hazards Earth Syst. Sci., 14, 901-916, doi:10.5194/nhess-14-901-2014, 2014.

Paudel, Y., Botzen, W. J. W., and Aerts, J. C. J. H.: Estimation of insurance premiums for coverage against natural disaster risk: an application of Bayesian Inference, Nat. Hazards Earth Syst. Sci., 13, 737-754, doi:10.5194/nhess-13-737-2013, 2013.

Petrucci, O.: Brief communication "The assessment of damage caused by historical landslide events", Nat. Hazards Earth Syst. Sci., 13, 755-761, doi:10.5194/nhess-13-755-2013, 2013.

Pfurtscheller, C.: Regional economic impacts of natural hazards the case of the 2005 Alpine flood event in Tyrol (Austria), Nat. Hazards Earth Syst. Sci., 14, 359-378, doi:10.5194/nhess-14359-2014, 2014.

Poussin, J. K., Bubeck, P., Aerts, J. C. J. H., and Ward, P. J.: Potential of semi-structural and non-structural adaptation strategies to reduce future flood risk: case study for the Meuse, Nat. Hazards Earth Syst. Sci., 12, 3455-3471, doi:10.5194/nhess-123455-2012, 2012.

Rheinberger, C. M., Romang, H. E., and Bründl, M.: Proportional loss functions for debris flow events, Nat. Hazards Earth Syst. Sci., 13, 2147-2156, doi:10.5194/nhess-13-2147-2013, 2013.

Schröter, K., Kreibich, H., Vogel, K., Riggelsen, C., Scherbaum, F., Merz, B.: How useful are complex flood damage models?, Water Resour. Res., 50, 3378-3395, 2014. 
Schröter, K., Kunz, M., Elmer, F., Mühr, B., and Merz, B.: What made the June 2013 flood in Germany an exceptional event? A hydro-meteorological evaluation, Hydrol. Earth Syst. Sci., 19, 309-327, doi:10.5194/hess-19-309-2015, 2015.

Schwendtner, B., Papathoma-Köhle, M., and Glade, T.: Risk evolution: how can changes in the built environment influence the potential loss of natural hazards?, Nat. Hazards Earth Syst. Sci., 13, 2195-2207, doi:10.5194/nhess-13-2195-2013, 2013.
Seifert, I., Kreibich, H., Merz, B., Thieken, A. H.: Application and validation of FLEMOcs - a flood loss estimation model for the commercial sector, Hydrol. Sci. J., 55, 1315-1324, 2010. 